\title{
Entre proteção, exposição e admissóes condicionadas: travestilidades e espaços de sociabilidade ${ }^{1}$
}

\author{
Gustavo Artur Monzelia, Vítor Sérgio Ferreira ${ }^{b}$, Roseli Esquerdo Lopes ${ }^{c}$ \\ ${ }^{a}$ Universidade Federal do Espírito Santo - UFES, Vitória, ES, Brasil. \\ 'Instituto de Ciências Sociais, Universidade de Lisboa, Lisboa, Portugal. \\ 'Universidade Federal de São Carlos - UFSCar, São Carlos, SP, Brasil.
}

\begin{abstract}
Resumo: O objetivo deste trabalho foi compreender, tomando-se a vivência com quatro jovens que, em algum momento da pesquisa que os integra, se autodenominaram travestis, residentes na cidade de São Carlos-SP, as principais técnicas e estratégias utilizadas por elas para o manejo e a manipulação de suas características corporais, subjetivas e identitárias, a fim de se inserirem e circularem em determinados espaços de sociabilidade. Dado seu objeto, resta clara a importância das inspirações e contribuições etnográficas, enquanto uma metodologia que pôde fornecer os caminhos para a busca de respostas aos questionamentos desta pesquisa. Pondera-se a multiplicidade de formas de considerar e construir signos do que é tido como feminino em corpos assignados como masculinos. Discutem-se as estratégias utilizadas pelas jovens travestis para se inserirem em diferentes configurações familiares, na escola e na prostituição. No contexto dessas histórias de proteções e exposições, problematiza-se a pertinência das possíveis contribuições da terapia ocupacional nesse âmbito, mais especificamente para a terapia ocupacional social. Essas jovens, em diferentes níveis de conscientização, identificam os espaços pelos quais podem circular mais livremente e os espaços onde devem ser mais cautelosas, conformando suas características corporais, subjetivas e identitárias. Serem aceitas - ou não - nos diferentes espaços não repercute "apenas" na inserção ou na restrição da participação e do exercício de direitos e da própria cidadania, mas, sobretudo, reverbera em suas próprias subjetividades, pois acabam por explicitar possibilidades e impossibilidades de "ir e vir" nos espaços privados e/ou públicos, e, especialmente, a possibilidade ou a impossibilidade de existir nesses locais.
\end{abstract}

Palavras-chave: Terapia Ocupacional Social, Sexualidade, Gênero, Travestilidade.

\section{Among protection, exposure and conditioned admissions: travestilities and sociability spaces}

\begin{abstract}
This study aimed to understand, considering the experience of four young people who called themselves "transvestites" at some point during the research, residing in São Carlos (SP), the main techniques and strategies used by them for the manipulation of their own characteristics regarding their body, subjectivity and identity, in order to participate in certain spaces of sociability. Their aspirations and ethnographic contributions remain as clearly important methods to provide the demand for answers to questions of this research. This paper considers the multiplicity of ways to construct signs of what is considered feminine in bodies assigned as male. We discuss the strategies used by young transvestites to participate in different contexts such as family, school and prostitution. And in this context of these stories of protections and exposures these different realities are configured as an important issue for occupational therapy, specifically for social occupational therapy. These young transvestites,
\end{abstract}

Autor para correspondência: Gustavo Artur Monzeli, Universidade Federal do Espírito Santo, Avenida Marechal Campos, 1468, Maruípe, CEP 29040-090, Vitória, ES, Brasil, e-mail: gustavo.monzeli@gmail.com 
at different levels of awareness, identify the areas in which they can move more freely and the spaces where they should be more cautious, shaping your body, and subjective identity characteristics. Be accepted in different areas reverberates not "just" the inclusion or participation restriction and exercise of rights and citizenship itself, but especially reverberates in their own subjectivities therefore explain possibilities and impossibilities of "coming and going" in private or public spaces and especially the possibility to exist in these places.

Keywords: Social Occupational Therapy, Sexuality, Gender, Transvestility.

\section{Introdução}

Este artigo é um dos resultados de uma pesquisa de Mestrado que emergem da proposição da articulação teórico-metodológica, partindo de uma inserçáo nas experiências de intervenção que, advindas de demandas relacionadas a um campo específico de ensino-pesquisa-extensão, o METUIA/UFSCar, vem realizando em parceria com equipamentos sociais, como uma Escola Pública e um Centro da Juventude ${ }^{2}$, localizados em bairros da Grande Cidade Aracy, região periférica da cidade de São Carlos-SP.

Essa inserção tem proporcionado a percepção e a reflexão de diferentes questôes relacionadas às possibilidades de compreensão e expressão de identidades e subjetividades dos diversos jovens que ali vivem.

Dadas tais configuraçôes e os contatos estabelecidos, as questóes relacionadas às travestilidades ${ }^{3}$, no âmbito mais geral dessa cidade e naquele mais específico dessa região, começaram a se tornar evidentes aos nossos olhos, uma vez que a circulação de algumas jovens estudantes "travestis" deflagrou a incapacidade da instituição escolar em conviver com determinadas diferenças. É importante ressaltar que a escolha da palavra "conviver" demonstra a impossibilidade de existência de determinadas experiências corporaissubjetivas-identitárias, no contexto escolar.

O "problema" para a escola começou no momento em que passaram a ocorrer conflitos ligados ao fato de algumas dessas jovens decidirem frequentá-la com roupas e adereços identificados como femininos, como, por exemplo, a utilizaçáo de batom, esmalte nas unhas, pulseiras, dentre outros acessórios.

Da mesma forma que eram incorporados tais adereços por elas, aumentavam proporcionalmente as tentativas de intervençáo dos profissionais da escola, no sentido de tentar minimizar a visibilidade do que era percebido como problemas gerados pela presença dessas jovens e seus adereços femininos no ambiente escolar.

Questionamo-nos, então, em que medida estes lugares institucionais se diferenciavam das esquinas, local que elas já frequentavam e onde trabalhavam, em relação à exposição, aos insultos e às violências cotidianas; concomitantemente, nos deparávamos com muitas ambiguidades nas relações e nos espaços frequentados por elas, e também por nós. A esquina que expóe e violenta é a mesma que acolhe e dá prazer, a instituição que deveria acolher e educar é a mesma que expóe e violenta.

O objetivo principal da pesquisa empreendida foi compreender, tomando-se a vivência com quatro jovens que, em algum momento da pesquisa, se autodenominaram travestis, residentes na cidade de São Carlos-SP, as principais técnicas e estratégias utilizadas por elas para o manejo e a manipulação de suas próprias características corporais, subjetivas e identitárias, a fim de se inserirem e circularem em determinados espaços de sociabilidade, especificamente os contextos familiares, de instituições formais de ensino e também de prostituição.

Apresentaremos aqui parte dos resultados dessa pesquisa, focalizando a discussão de tais espaços de sociabilidade e de suas possíveis implicaçôes na vida cotidiana dos sujeitos em seus territórios de pertencimento, apontando como a circulaçáo dessas jovens tem rebatimentos nos níveis de inserção, restringindo ou possibilitando suas existências em diferentes configuraçôes e formaçôes sociais (ELIAS, 2001).

As travestis são consideradas ambíguas por não se encaixarem na coerência entre sexo, identidade de gênero, orientação sexual e práticas sexuais. A premissa sexo-gênero-sexualidade afirma que o sexo indica determinado gênero e este gênero, por sua vez, induz o desejo. Nessa lógica, supóe-se que o sexo é natural e se entende o natural como dado. O sexo existiria antes da inteligibilidade, seria pré-discursivo, anterior à cultura (LOURO, 2004), e cada cultura moldaria, imprimiria, suas marcas nesse corpo inerte e diferenciado sexualmente pela natureza (BENTO, 2006).

Essa lógica é completamente subvertida por diversas experiências identitárias relacionadas ao sexo, ao gênero e à sexualidade. As travestis, por exemplo, bagunçam tal premissa ao realizarem uma construção corporal carregada de signos femininos partindo de um corpo assignado como masculino, além de se tratarem com o artigo feminino ("a travesti”) e, ao mesmo tempo, realizarem práticas 
sexuais consideradas masculinas. É claro que essa subversão não é específica para as travestis, uma vez que os próprios clientes que realizam os programas sexuais com elas são (em grande maioria) homens, que se tratam com o artigo masculino ("o pai-defamília”) e, ao mesmo tempo, realizam práticas sexuais consideradas femininas.

\section{Caminhos metodológicos}

Com base no entendimento de que a tentativa de reconstituição das trajetórias de vida é necessária para a compreensão e a problematizaçâo das possibilidades atuais de inserçáo nos contextos relacionais e de trabalho dos sujeitos, resta clara a importância das inspiraçốes e contribuiçôes etnográficas, enquanto uma metodologia de pesquisa que pôde fornecer os caminhos para a busca das respostas aos questionamentos desta pesquisa.

A pesquisa de caráter etnográfico não se caracteriza como um estudo longitudinal, que abarca grandes contingentes populacionais, na busca explicativa de relaçôes entre variáveis; ao contrário, concentra-se em pequenos grupos para empreender um estudo em profundidade, de maneira a interpretar significados de práticas, motivaçôes, rituais, crenças, etc. (VILA et al., 2007).

Nessa direção, durante todo o período de campo, que aconteceu entre os meses de julho de 2011 a junho de 2012, as quatro jovens ${ }^{5}$ que mais contribuíram para a pesquisa foram Simone, Melissa, Claudinho e Jonas ${ }^{6}$. Simone tinha 16 anos no início e acabava de completar 17 anos no final de nossa pesquisa de campo; Melissa, Claudinho e Jonas tinham 17 anos no início e todas completaram 18 anos no final de nossas incursóes em campo.

Com relação a esta pesquisa, todas as jovens foram acompanhadas no período acima mencionado, o que ocorria com frequência variada: em algumas semanas, eram dois ou três encontros, enquanto em outros momentos da pesquisa, os acompanhamentos eram praticamente diários.

A participação em campo era bastante fluida e dependia muito da articulação da rotina de todos os envolvidos nesse processo, levando a um acompanhamento ora realizado cotidianamente com nossa presença física ora efetivado por ligaçóes telefônicas e/ou contatos via internet. Com graus e momentos diferenciados de presença - e também de ausência -, todas compartilharam conosco trechos e recortes de suas vidas.

Fez parte do aprofundamento nas biografias, a convivência cotidiana com elas em diferentes contextos, quais sejam: em casa, na escola, nos equipamentos de saúde, na "balada”, na igreja ou na esquina. As temáticas surgiam das diversas situaçôes que se tornavam reais por meio de nossa presença ou através de seus próprios discursos. Foi assim que pudemos perceber e compreender com mais nitidez alguns traços/trechos (PAIS, 2001) dessas vidas.

Tomando-se o registro sistemático das vivências em diários de campo, realizado imediatamente após cada incursão, aliado à descrição densa (GEERTZ, 1978) de situações de interação, analisamos os dados trazidos. A construção e a reflexão em torno dos diários de campo nos auxiliavam a compreender melhor e a sistematizar as trajetórias de vida das jovens colaboradoras, apontando e organizando as principais questóes que surgiam da vivência cotidiana com elas.

Diferentemente do que aconteceu, por exemplo, na etnografia de Barbosa (2010), na qual ele acompanhou algumas pessoas "trans" com idade aproximada entre 40 e 60 anos, e que tentavam trazer certa coerência nos relatos biográficos, o que ele chamou de "coerência do eu", as interlocutoras desta pesquisa, por serem muito jovens, não possuíam longas "trajetórias" e "histórias" de vida, mas um tecer cotidiano editado e reeditado através de suas próprias narrativas.

É claro que estas jovens, mesmo não tendo percorrido extensos trajetos de vida, podem aglutinar longas experiências de privaçáo e exclusão, e os sujeitos mais velhos podem editar e reeditar suas trajetórias partindo de suas narrativas e práticas, mas o que fica evidente, na vida destas jovens, que pudemos acompanhar, é que elas vivenciam grandes experiências e transformaçôes cotidianas em seus desejos, em suas identidades e em seus corpos, talvez se preocupando menos com as coerências biográficas e mais com os relatos daquilo que vivenciam.

\section{Resultados e discussões}

\subsection{Com o salto em casa ou na bolsa: sobre laços e famílias}

Durante o tempo de pesquisa de campo, pudemos nos aproximar ainda mais das famílias de Melissa e Jonas, e acompanhar, embora de maneira um pouco mais distante, as famílias de Claudinho e Simone.

Todas as jovens que colaboraram com este estudo continuam morando em casa e vivendo com suas famílias, o que já tinha sido observado por Duque (2009), quando sugere que:

a despeito de toda homofobia a que estão expostos em casa desde a infância (BENEDETTI, 2005), parte dos sujeitos 
que tenho pesquisado, não tem rompido os laços com seus familiares. Diferentemente do que ocorria frequentemente com a geração anterior, muitas travestis adolescentes não têm sido expulsas de casa por seus pais, apresentando uma realidade bastante diferente daquela descrita por Pelúcio (2007), em que as travestis, quando se "assumiam", tinham o espaço doméstico da família, via de regra, insustentável (DUQUE, 2009, p. 79).

Melissa é a única que, ainda hoje, utiliza roupas e adereços femininos em todos os espaços que frequenta, desde as ruas do bairro até dentro da própria casa. Seus familiares acompanharam todo o processo de sua transformação corporal e estética, e sabem que todas as noites, quando sai de casa, ela vai para a Avenida Getúlio Vargas ${ }^{7}$ trabalhar.

Ela mora com a mãe e o padrasto, ambos frequentadores de uma igreja neopentecostal. Apesar da formação religiosa rígida sobre as concepçôes de homem, mulher e família, eles não encaram o investimento nos processos de travestilidade de Melissa como um problema, mas, pelo contrário: em alguns momentos, eles até demonstram certa admiração, como, por exemplo, quando nos mostram fotos das performances que ela faz em algumas boates da região de São Carlos.

Para eles, o único problema é a relação de Melissa com os espaços de prostituição, pois eles sempre falam com muita preocupação sobre todos os tipos de violência a que ela está exposta nas ruas e esquinas em que trabalha, ainda mais por saberem que ela frequenta os espaços de prostituição de rua desde os 14 anos.

Já para a família de Jonas, o grande problema não é nem o investimento nos processos de transformação corporal, nem a exposição à violência das ruas, mas a relação que ele tem com as substâncias psicoativas lícitas e ilícitas.

Pelo discurso de sua mãe e de suas irmãs, o problema está na utilização das drogas, o que, para elas, está diretamente relacionado com a montagem e a ida aos lugares de prostituiçáo; na leitura que fazem, a saia, a maquiagem e o salto alto significam prostituição, o que concomitantemente se transforma em uso de drogas.

A relação que Jonas constituiu com algumas substâncias psicoativas ilícitas fez com que a família, juntamente com o Conselho Tutelar e o Centro de Atenção Psicossocial (CAPS/AD), decidisse pela internação de Jonas em uma Comunidade Terapêutica para a desintoxicação e a "cura do vício" pela abstinência.
A principal questão é que esta Comunidade Terapêutica, apesar de conveniada ao setor de saúde pública da cidade, possui diretrizes de "cuidado" baseadas em crenças, valores e preceitos religiosos. Desse modo, os processos de atenção em saúde, mesmo do setor público, se misturam a procedimentos de cunho privado e religioso, numa atuação que reúne aportes "supostamente" profissionais/científicos e preceitos valorativos e de fé, na direção da imposição da transformação de práticas, comportamentos, subjetividades e corpos. Nessa instituição, Jonas só podia ser "cuidado" e existir no "masculino".

Com a família de Claudinho, nossa relação foi um pouco mais complicada, pois nunca soubemos ao certo o quanto seus pais e irmáos sabiam de suas montagens e de sua circulação nos espaços de prostituição de rua, e exatamente por náo saber, náo nos sentíamos à vontade para abordar estes assuntos em nossas conversas.

Todas as vezes em que encontramos Claudinho em casa, ele estava fazendo a linha boyzinho ${ }^{8}$, com uma roupa mais ou menos apertada, mas nunca um adereço feminino, às vezes apenas traços e restos de maquiagem da noite anterior. Por considerar sua família bastante religiosa e conservadora, Claudinho não se monta em sua própria casa e, quando sai à noite, coloca suas roupas, o picumã ${ }^{9}$ e o salto na bolsa, e vai para a casa de alguma amiga, onde pode mais livremente se vestir para a noite.

Para Simone, sua família aceita bem o fato de ela se relacionar afetiva e sexualmente com rapazes, e também às vezes se montar dentro e fora de casa. Ela diz que sua mãe gosta de lhe ajudar a escolher uma ou outra roupa para sair de casa e, ao mesmo tempo, sempre quer que Simone dê suas opinióes para roupas e acessórios, bem como para fazer sua maquiagem e diferentes penteados, por achar que o filho tem muita habilidade nessa área.

Diferentemente da situação de Melissa, para a qual o salto e a minissaia já fazem parte da vivência familiar, para as famílias de Jonas e Claudinho, os investimentos delas nos processos de travestilidade significam, dentre outras possíveis violências, a vivência na prostituição e o acesso às substâncias psicoativas ilícitas.

É interessante perceber nos discursos de Melissa, Jonas, Claudinho e Simone que grande parte da vida social delas está dividida entre dentro e fora da casa dos pais. Esta dualidade possui outras reverberaçōes: dentro de casa é o lugar reservado para as atitudes e situaçóes consideradas corretas, ao passo que o fora de casa se reserva aos erros e situaçóes menos valorizadas; isso tudo se dá dentro de uma lógica burguesa e cristã de "certo" e "errado", o que parece 
integrar uma experiência mais geral, comum entre diferentes jovens.

Apesar de não serem burguesas nem necessariamente cristâs, elas muitas vezes partilham dos valores culturais estabelecidos e valorizados como norma, e, não obstante, constroem seus corpos, identidades e subjetividades sempre na relação entre as demandas e expectativas de normatização e suas próprias vontades e desejos.

É esta lógica que permite à Melissa negociar a entrada de um namorado na casa de seus pais, pois, quando a mãe, a princípio, nega a presença do namorado, Melissa utiliza o argumento de que é melhor ela estar namorando dentro de casa, perto dos olhos dos pais, do que passar a noite fora de casa, longe do alcance da família e exposta a violências.

Assim como Melissa, Simone utiliza a mesma estratégia para conseguir que a mãe lhe ajude na compra de materiais e instrumentos para seu trabalho como cabelereira, argumentando que é melhor ela trabalhar como cabelereira dentro de casa do que ir à Avenida Getúlio Vargas para trabalhar nos espaços de prostituição.

Este dentro e fora é cotidianamente negociado entre elas e seus familiares, alimentado e realimentado nesse contexto; elas conseguem, em diferentes níveis, subverter essa mesma lógica na qual se baseiam.

Dessa forma, para além das ajudas financeiras, o não rompimento dos laços familiares certamente é um dado importante na medida em que a estadia prolongada na casa dos pais, em variados níveis de consciência e de concordância sobre os processos de travestilidade dos filhos, influencia tanto em questôes dos espaços de sociabilidade quanto na constituiçáo das redes de suporte social e pessoal, reposicionando algumas dessas jovens nas diferentes configuraçôes familiares.

\section{2 $\mathrm{Na}$ pista, entre gentes e carros que têm gentes}

Andar pela noite da Avenida Getúlio Vargas com Melissa é sempre uma aventura. Assim como as outras jovens que participaram desta pesquisa, ela começou a ter experiências esporádicas com o mercado do sexo pago desde aproximadamente o início de seus 14 anos. Por frequentar esse espaço há muito tempo, conhece bem os lugares onde pode ou não estar, assim como, dentre aqueles em que ela pode estar, os que são melhores para o início ou para o fim da noite.

Esta regiāo da Avenida Getúlio Vargas - ou "Gê", como Melissa gostava de chamar para demonstrar sua intimidade com os espaços - se constitui como uma multiterritorialidade (HAESBAERT, 2004), na medida em que durante o dia se caracteriza como área de comércio automotivo - com inúmeras lojas concessionárias para venda de carros, desde os chamados "populares" até os mais luxuosos, além de inúmeros postos de combustível e oficinas mecânicas, por ser uma das principais vias de entrada/saída da cidade - e, durante o período noturno, suas ruas se transformam em espaços de prostituição feminina, de mulheres e travestis.

Caminhando com Melissa à noite, pela Getúlio, logo paramos em uma das esquinas onde ela frequentemente prefere ficar e sentamos em uma mureta de concreto um pouco mais afastada, para não atrapalhar o fluxo ou espantar os clientes.

As ruas estão um tanto vazias, o baixo trânsito é formado por carros passando para diferentes lugares e com diversas velocidades, apesar de também se perceber algumas motos, bicicletas e, às vezes, pessoas caminhando. Há carros importados, populares e, em um determinado momento, uma carroça.

Enquanto os carros passam, Melissa ora se penteia e corrige o batom, ora diminui a saia e ajeita a neca $^{10}$. As cabeças das pessoas no interior dos carros - $\mathrm{e}$ também a de Melissa - rodam assim como rodam seus corpos, à procura de algo, ainda não se sabe o quê, podemos supor.

O interior dos carros ora são mundos inacessíveis ora são grande exibição. O que é individualidade para uns pode ser extrema exposição para outros. $\mathrm{O}$ carro que dá a volta e revolta, e volta mais uma vez, pode ser o que possibilite o próximo dinheiro, o próximo piris $^{11}$, a próxima agressão, o próximo namorado ou a próxima carona para casa. Pode ser o privilégio da segurança para uns ou a ameaça desconhecida para outros, mas ambos permitem acessos.

Acesso ao prazer, ao dinheiro, à materialização do desejo. Acesso a lugares, a mundos que se chocam, se encontram, se abraçam, se penetram. O carro que pode levar ao motel, nesse instante, pode levar ao matagal, ou para casa, ou para a delegacia, ainda não se sabe, se espera. A espera pode gerar tensão, mas pode também dar prazer, tesão e medo, todos esses sentimentos, expectativas e emoçóes se misturam antes que o carro pare.

Com a mesma velocidade em que o caro vai parando, a frequência cardíaca começa a aumentar. O carro para, o coração dispara e as pernas se movimentam rijas em direção ao desconhecido, por vezes conhecido até demais. Nessa hora, se engole a saliva seca e se vai, torcendo para que seja bom. Bom, certamente, é o caminhar até o carro, quase como em um desfile, fazendo a linha Gisele ${ }^{12}$ na passarela: este é um dos principais momentos, a 
negociação. Antes eram corpos isolados, um mais protegido pelo carro e outro mais exposto pela esquina, mas agora o carro já está parado e os dois corpos bem mais próximos.

O desfile serve tanto para aproximar os corpos quanto para avaliar as possibilidades de se efetivar o programa sexual. Enquanto caminha, Melissa observa o carro e as próprias condições deste (se é novo, velho, usado, importado, se tem vidros automáticos, travas elétricas, etc.), como também a pessoa que está no carro (se é jovem, velho, maricona ${ }^{13}$, sarado $0^{14}$, se é provavelmente ativo ou passivo sexualmente, se está sozinho ou com amigo, namorado ou namorada, etc.). Já para o sujeito (ou sujeitos) dentro do carro, esses segundos funcionam como uma última avaliação, no sentido de verificar se a escolha foi a melhor para a realização do programa.

Depois do desfile e das primeiras palavras trocadas, o próximo momento pode ter dois rumos, um é voltar para a esquina, o que poucas vezes acontece, dado todo esse processo de sedução inicial, e o outro é a porta do carro que se abre. Quando esta segunda opção acontece, Melissa já sabe que alguma coisa ela vai conseguir.

Melissa nos contou de casos nos quais ela foi convidada a entrar no carro e, logo após um pouco tempo de conversa, o cliente desistiu de realizar o programa sexual, o que para ela - e para muitas outras pessoas que trabalham no contexto do sexo pago - é motivo de confusão, pois, uma vez que se está dentro do carro, o programa começa, com o possível cliente querendo ou não; ele tem que pagar pelo tempo disponibilizado por ela, mesmo que tenha sido um "tempo perdido". Nestes casos de clientes que desistem do programa, a solução encontrada por Melissa é "travar o carro"15 e esperar que ou o cliente pague ou que o carro seja danificado.

Lança-se mão de diferentes estratégias de sobrevivência cotidiana, incluindo-se o conseguir, de certa forma, revidar algumas situações de extrema violência.

Possivelmente, essas estratégias nem sempre funcionam com todos os clientes e em todas as situaçôes; por isso, uma "tamancada" para quebrar o vidro do carro, às vezes, é o que dá para fazer, e, em outras ocasióes, correr é apenas o que resta.

Como já bem discutido em outras etnografias com travestis sobre os contextos do mercado do sexo pago (PELÚCIO, 2007; SILVA, 1993; BENEDETTI, 2005; DUQUE, 2009), assim como na etnografia de Perlongher (1987) sobre as experiências dos michês, a entrada nos contextos da prostituição não é apenas resultante da impossibilidade de acesso aos "[...] paradigmas da normalidade, mas da afirmatividade de uma recusa fatual. A recusa à disciplina do trabalho e à lógica da ordem pode assumir formas diretamente delinquenciais [...]" (PERLONGHER, 1987, p.204). O estudo desse autor aponta para os itinerários da "[...] prostituição como expressão da recusa destes paradigmas de normalidade [...]" (DUQUE, 2009, p.40).

Mais do que formas de resistência e recusa de paradigmas, a prostituiçáo aparece como um espaço que proporciona autonomia, na medida em que viabiliza um rendimento financeiro e, sobretudo, como meio e reconhecimento de possibilidade de existência.

Este é um importante deslocamento, uma vez que os contextos da prostituiçáo deixam de ser considerados apenas como lugar de exposição, exploração e violência para serem compreendidos como importantes espaços de sociabilidade (BENEDETTI, 2005) e aprendizagem de técnicas de construção corporal - inclusive técnicas de sobrevivência - para algumas jovens.

Na sociabilidade do mercado do sexo, muitos encontram reconhecimento e aprendem com seus pares as técnicas corporais para construírem sua desejada estética particular. No caso das travestis, o processo inicia com o consumo de hormônios femininos indicados pelas mais experientes (DUQUE, 2009, p.40).

No cotidiano de Melissa, a prostituição, além de ser o principal meio de conseguir dinheiro, para ela e para a família - pois, com o dinheiro que ganha na noite, ela consegue ajudar a pagar algumas contas da casa -, é um dos poucos lugares em que ela pode efetivamente se montar e, também, ser valorizada por sua beleza feminina. A ideia de ser desejada na noite e que os bofes pagam para estar com ela transforma a "bicha pobre que apanha no banheiro da escola" em uma "bela travesti desejável para os bofes".

\subsection{Apenas gayzinhos, ou onde começam os babados na escola}

As histórias de Melissa, Jonas e Claudinho com a escola são muito parecidas; apesar dos fluxos de desistência/retorno/permanência/desistência, todas estudaram na mesma escola e frequentaram as aulas até atingirem certa formação similar, o Ensino Fundamental incompleto.

Conhecemos as três quando se consideravam gayzinhos, mais ou menos afeminados, dependendo do contexto. $\mathrm{O}$ momento em que eles começaram a ir para a escola vestindo acessórios femininos foi quando a escola começou a encarar esta situação como uma questáo, um problema. 
Segundo as jovens, a diretoria da instituição oficialmente nunca tinha chamado nenhuma das três para uma conversa sobre os problemas e as dificuldades que elas enfrentariam na escola por serem consideradas gays ou por desfilarem pelos corredores "todas pintosas" 16 . Para elas, a situaçâo só se tornou uma questão quando os acessórios femininos começaram a fazer parte do vestuário cotidiano, inclusive dentro da escola.

Quanto mais aumentavam os acessórios, mais esta relação se tornava um problema para a escola. $\mathrm{O}$ que antes era ignorado ou náo percebido, voluntária ou involuntariamente, passa a ter uma grande visibilidade.

Esse aumento de visibilidade era, ao mesmo tempo, percebido pela reação dos outros meninos e meninas da escola, que se misturava entre amores e ódios, como elas gostavam de dizer, entre comentários e olhares deslumbrados e grotescos, entre desejos e abjeçôes.

É interessante perceber que, para elas, na relação com a escola e com os outros estudantes, existe uma diferença importante entre o "antes" e o "depois" de começar a se montar. Um antes talvez marcado por um "passar desapercebido" e um depois caracterizado por tudo, menos a invisibilidade nos corredores da escola.

Isso não significa que quando elas faziam a linha gayzinho eram mais bem aceitas ou não tinham nenhum tipo de problemas com os outros alunos, até porque, como elas nos contavam, os babados e as confusóes já aconteciam, havia muito tempo, nos banheiros da escola.

O que se quer dizer é que, para a percepção da escola, a montagem no ambiente escolar, pelo menos naquele momento, era o limite do aceitável, pois, enquanto elas iam para a escola "apenas gayzinhos" era como se náo existisse um problema, uma questão a ser percebida e resolvida pela direção, mesmo que elas apanhassem ou atendessem ${ }^{17}$ os boys ${ }^{18}$ no banheiro da escola. A questão e o problema surgem quando os adereços femininos começam a ficar mais presentes nesse ambiente.

Naquela época, as três tinham por volta de 14 anos e estudavam, como sempre fizeram, no período diurno, quando a direçáo da escola as chama para uma conversa sobre os problemas que estavam acontecendo e, como solução, sugere a transferências das três para o período noturno, com a alegaçáo de que elas seriam mais bem aceitas pelos alunos mais velhos, que frequentam a escola no período noturno e, ao mesmo tempo, não seriam má influência para as crianças que estudam durante o dia.
Depois da transferência de horários, os problemas não se solucionam, nem diminuem. Elas continuam frequentando a escola com acessórios femininos e permanecem as dificuldades na hora da "chamada"19, na hora do intervalo ou na hora de utilizar os banheiros.

Jonas nos conta que a última conversa com a escola foi um pouco mais difícil. A última "solução" encontrada pela direção foi dizer que elas eram muito bem aceitas na escola, mas que se quisessem frequentar as aulas, elas teriam de ir vestidos como meninos, porque de outra maneira não entrariam na escola.

A transferência para o período noturno foi difícil, em um primeiro momento, porque os horários das aulas coincidiam com os horários do trabalho, na medida em que as três já frequentavam a Avenida Getúlio Vargas com certa assiduidade; e, depois dessa intervenção e da impossibilidade de elas irem para a escola montadas, cada vez mais a vontade e o interesse em estar na escola foram diminuindo, sendo que as três resolveram, aos poucos, parar de frequentar o ambiente escolar.

O babado na escola passa também pelos banheiros. A porta com um símbolo masculino ou feminino funciona como um filtro que, além de separar os elementos, acaba identificando e expondo algumas diferenças. Muitos são os símbolos para apenas duas possibilidades de portas, como aponta Beatriz Preciado, pois os emblemas são praticamente uma interpelação de gênero: "[...] masculino ou feminino, damas ou cavalheiros, cartola masculina ou chapéu feminino, bigodes ou flores, como se as pessoas tivessem que ir ao banheiro mais para reafirmar seu gênero do que se livrar da urina e das fezes [...]" (PRECIADO, 2014, p. 1, tradução livre).

No ambiente escolar, os banheiros possuem um caráter de definição, exposição e reiteração das normas de sexo e de gênero, sempre situadas de uma forma heteronormativa, ou seja:

[...] os banheiros são espaços de alta densidade simbólica para a investigação das relaçóes de gênero e sexualidade no contexto público e escolar. Materializam e expressam concepçóes e práticas de cuidado do corpo e do meio ambiente [...] marcadas por significados de sexo e gênero (TEIXEIRA; RAPOSO, 2008, p. 1).

Conforme Cruz (2011, p. 78), “[...] nosso binário modo de funcionar dividiu os meninos-pênis para um banheiro e as meninas-vaginas para outro. Quando no cotidiano da escola (e das sociedades) surgem aqueles que fogem ao processo classificatório instituído, a confusão se estabelece”. Assim, não há espaços, nem banheiros, que consigam conceber a existência 
de uma menina-pênis ou um menino-vagina, visto que estes corpos, antes de tudo, não são inteligíveis.

No momento em que uma pessoa se direciona a uma das duas opçôes de portas, acontece um posicionamento que atravessa o plano individual e subjetivo, e alcança níveis de identificação coletiva; o direcionamento, para além de uma escolha consciente, é também uma identificação e uma exposição.

Simone continua estudando e, atualmente, está cursando o segundo ano do Ensino Médio em uma escola diferente da que as outras três jovens estudam. Ela não se sente à vontade para utilizar a porta masculina e, mais recentemente, não se sente habilitada a entrar no banheiro feminino; algumas confusôes já aconteceram fora e dentro dessas portas, desde brincadeiras maldosas quando ela usava o lado masculino até uma advertência da direção que a proibiu de utilizar o banheiro feminino.

Quando ela se dirige ao lado masculino, decide não entrar porque reconhece que neste local ela não é filtrada totalmente, ficam presos e expostos seus cílios postiços, maquiagem e alguns esmaltes, além de saber que esta porta pode representar exposição a tipos de violência por parte dos garotos que entram e saem livremente por essa passagem.

Ao mesmo tempo, ela não consegue utilizar o banheiro feminino porque as regras da instituição escolar, e não especificamente desta escola, criam outro impedimento, um filtro bastante acurado que novamente não consegue filtrá-la por completo e, desta vez, o que a impede de passar pela porta das meninas é seu pênis.

Entretanto, uma hora ou outra, todos precisam utilizar o banheiro, inclusive as travestis. Em algumas situaçôes, Simone declarou que tenta não tomar muita água durante o tempo em que está na escola para não precisar ir ao banheiro e, recorrentemente, tem que "se segurar" durante todo o período, para conseguir utilizar o banheiro apenas em sua casa, onde ela pode entrar e sair sem se preocupar com os processos de filtração.

Como, neste momento, o transtorno é a porta, ou melhor, o problema é a Simone que não consegue se encaixar em nenhuma das portas, a solução que a escola encontrou e sugeriu foi a criação de uma terceira porta. Na verdade, esta terceira porta é um banheirinho escondido e isolado do pátio onde todos os alunos ficam durante o intervalo das aulas e os banheiros masculino e feminino se localizam.

Este banheirinho sem luz e, às vezes, sem água é o filtro por onde Simone pode passar totalmente, é o local reservado e exclusivo para ela, é sua "esquina" dentro da escola, onde pode estar e existir. Estes jogos de visibilidade e invisibilidade, existência e inexistência, são constantes na vida de Simone, não exclusivos a ela, mas ocorrem reiteradamente em seu cotidiano.

O dispositivo da sexualidade se reconfigura e se reatualiza nessa cena, mostrando os limites do aceitável e do inaceitável, do que pode ser visível e do que precisa ser escondido, exibindo constantemente que as fronteiras existem e que o câmbio e o próprio limite interfronteiras são perigosamente instáveis e ameaçadores. Portanto, para os que não se encaixam nos símbolos normativos do masculino e do feminino, existe sempre - ou nem sempre? - um banheirinho escondido e sem luz.

As diferenças de localização entre os banheiros posicionam não só quem precisa utilizar o banheiro escondido, mas, principalmente, recoloca no centro da vida social - no caso, o pátio - os sujeitos normatizados (meninos e meninas). Nesta situação, não existe um sujeito que é escondido e um que é visualizado, o que acontece é que a situação se configura de um jeito em que a diferença geográfica expóe relaçóes de interdependência e hierarquias que reatualizam os próprios limites.

\subsection{Montagens e desmontagens para a terapia ocupacional}

Tomando-se a crítica elaborada por parte de alguns terapeutas ocupacionais em relação às bases e aos fundamentos das ações profissionais, as questôes sociais tornam-se elementos intrínsecos de uma determinada terapia ocupacional no Brasil (BARROS; GHIRARDI; LOPES, 2002).

No início da década de 1980, no Brasil, os profissionais, preocupados com a dinâmica social geradora de um quadro de extremas desigualdades sociais, buscavam discutir tais questóes no âmbito da própria disciplina, perguntando se esse seria um campo com objeto e método específicos de atuação. Esse debate permitiu que se percebessem os riscos e a necessidade de se definirem os limites da profissionalidade, evidenciando que a terapia ocupacional não se definia apenas no interior da própria profissão.

A proposta de uma terapia ocupacional social assume, nos anos de 1990, sentidos novos e diversas implicaçóes, resultado de esforços em renunciar à adoção de modelos redutores e de perspectivas simplificadoras para a compreensão das questóes sociais, redefinindo objetos e instrumentos de intervenção, estabelecendo a profissão em bases mais largas (BARROS; GHIRARDI; LOPES, 2002; BARROS, 2004). 
O foco central para as açóes dos terapeutas ocupacionais sai dos contextos individuais do sujeito (considerado corpo/mente doente ou desviante) e passa para as conjunçôes coletivas, nas quais os significados culturais não podem ser desconectados das vivências pessoais. Dessa forma, das ações centradas no indivíduo e em sua singularidade, passa-se a pensar, a considerar e a lidar com a coletividade e com as relaçóes estabelecidas, procurando compreender as interaçôes que atuam sobre os sujeitos, determinando as variadas formas e intensidades de vulnerabilização das redes sociais de suporte (LOPES et al., 2008).

Os contextos de ação dos profissionais se reconfiguram na medida em que os espaços institucionais e os chamados settings terapêuticos dáo lugar aos espaços da vida cotidiana, valorizando-se os territórios onde se vive, as configuraçôes das identidades e as diferentes formas de pertencimento dos sujeitos, individuais e coletivos.

A terapia ocupacional social, ao estruturar suas açóes no e/ou a partir dos territórios da existência, se depara com outras problemáticas que surgem deste movimento de "desinstitucionalização" de suas açôes profissionais, problemáticas para além das questōes de reabilitação ou de cuidado da saúde (BARROS; GHIRARDI; LOPES, 2002).

É na imersão nos diferentes territórios e nos fazeres cotidianos dos sujeitos que os técnicos podem conhecer e apreender, de maneira mais contundente, as alteridades e as diversidades culturais (BARROS; ALMEIDA; VECCHIA, 2007). Através do reconhecimento de outras maneiras de organização e de criação de sentido para as muitas açóes, os terapeutas ocupacionais podem se disponibilizar para a identificação das diferenças (étnicas, religiosas, sexuais, de classes sociais, de geração, etc.) e da produção das desigualdades sociais que as configuram.

Mostra-se essencial a aposta nas possibilidades de estímulo e apoio a modos distintos de resistência (individual e coletiva) à desumanização, inventando, em conjunto, formas de experimentação, aprendizagem, ensino e criação que combatam as desigualdades e contribuam para a construção de pontes de acesso a direitos, para a elaboração e a mobilização de processos orientados para a emancipaçáo pessoal (ALMEIDA et al., 2011).

Considerando-se as açóes que discutam a disponibilização de serviços mais inclusivos e a conscientização e a participação da comunidade nos processos de resolução dos problemas, a terapia ocupacional social pode ter um papel importante na dinâmica de articulação destes diferentes níveis, tentando contribuir para a ressignificação dos espaços públicos e institucionais, e para a percepção e a valorização de diversas demandas advindas das próprias comunidades.

Nesse sentido, identificamos a necessidade e a relevância em se desenvolver uma prática terapêuticoocupacional cientificamente fundamentada e não uma prática apenas impressionista e/ou burocrática, baseada em convençóes normativas acerca das realidades e vivências sociais, quase sempre ideológicas e fundadas em pré-conceitos.

Partimos da identificação, dentro do espaço institucional da escola, de um "comportamento" que era ali tomado como um "problema social", e cuja resolução passaria pela sua contenção: a montagem crescente de expressóes corporais de feminilidade por parte de alguns alunos à partida assignados como corpos masculinos.

Torna-se imprescindível ao profissional compreender que o "problema social” não está no fato de essas jovens vivenciarem esses processos de travestilidades, ou em suas montagens e desmontagens corporais, mas no fato de que essas instituiçôes, ao lidarem de forma preconceituosa com essas transformaçóes corporais, preservam as visóes estereotipadas que sobre elas recaem, reproduzindo, nas suas intervençôes, mecanismos de repressáo e estruturas de opressão, domesticação e docilização desses corpos e das experiências sociais que eles proporcionam e que, através destes, são vividas.

Perante essas novas realidades empíricas e até mesmo éticas para os terapeutas ocupacionais, procuramos compreender a alteridade que essas jovens representam a partir de suas próprias vivências nas microterritorialidades que habitam, tentando alargar o campo de possibilidades legítimas dentro das instituiçóes em que vivem e participam em sua vida cotidiana.

Aos terapeutas ocupacionais, implica propor açóes que não se justifiquem pela promoção da "adaptação social" de sujeitos "patologizados" às regras institucionais - no sentido da normatização de práticas, corpos e subjetividades -, mas efetivamente assumir, dentro do escopo da ação profissional, a necessidade de compreensão dos contextos coletivos, institucionais e de interação em que também esses sujeitos vivenciam seus cotidianos e dão valor e significados às suas práticas.

\section{Conclusões e alguns apontamentos}

Talvez o principal conflito existente nessas relaçóes institucionais já não seja o de acesso e integração dos sujeitos em diferentes níveis de assistência e serviços. Talvez a análise deva se direcionar para esta rede 
de serviços e instituiçóes que funciona de maneira seletiva, construindo cotidianamente fronteiras que mostram quem pode ser aceito e quem náo pode fazer parte desse enquadramento, ou melhor, quem deve se inserir nesse sistema de forma marginal.

Esse sistema de "proteção" formado por escola, equipamentos de assistência social e de saúde, ao mesmo tempo em que dizem da importância de se integrar, prescrevem os modos possíveis de se estar nesses contextos, produzindo "sintomas", estereotipando, criminalizando e/ou estigmatizando para selecionar.

Quando a escola, representada pela sua diretora, chega até Melissa, Claudinho e Jonas para discutir sobre a permanência delas nesse ambiente, ela só escolhe estas jovens porque o "sintoma" já foi diagnosticado. Este diagnóstico se relaciona com a articulaçáo das diferenças de gênero e sexualidade - não apenas, mas principalmente -, e com a inteligibilidade desses corpos no contexto escolar.

Nesse sentido, a instituição escolar que, no discurso e em termos legais, preza pela universalidade do acesso, acaba por evidenciar os pré-requisitos necessários para a admissão dos estudantes, sendo a coerência entre sexo, gênero e sexualidade uma importante condição, tendo como resultado a impossibilidade de acesso e circulação, nesse espaço, de algumas pessoas que não se enquadram nessas normas.

O acesso a serviços de saúde, como no caso da internação de Jonas em uma Comunidade Terapêutica devido à constatação de "uso abusivo de drogas", segue a mesma lógica da escola, na medida em que, para além do diagnóstico de "dependência química", existe um diagnóstico de incoerência da vida que, por razôes baseadas em preceitos religiosos ou mesmo de saúde, deslegitima práticas corporais, sexuais e de gênero, prescrevendo normativas que também funcionam como requisitos para a admissão no serviço de saúde, no qual as principais condições são: aparentar a masculinidade, a heterossexualidade e possuir um aspecto "saudável"20.

Essas admissóes condicionadas operam o papel seletivo e prescritivo dessas instituiçôes; assim, mesmo que a garantia de acesso, permanência e cuidado sejam seus princípios orientadores, quando se trata do contato com as alteridades e as diferenças étnicas, sexuais, religiosas, de classe social, entre outras, essas instituições continuam prescrevendo e reafirmando formas coerentes de acesso, inserção e participação.

A pista, que também tem suas normas e pré-requisitos, possibilita uma maior circulação e vivência dos processos de travestilidade; contudo, esses processos de construção corporal, subjetiva e identitária, funcionam igualmente de forma normativa, uma vez que prescrevem formas possíveis de se estar e de circular por esses locais. Não são todas as construçôes de feminilidade, assim como náo são todos os corpos que são reconhecidos e podem circular livremente neste contexto. Existe uma normatização do feminino almejado por elas - e por outras travestis - e desejado pelos possíveis clientes, conforme indicam outras etnografias (SILVA, 1993; BENEDETTI, 2005; PELÚCIO, 2007; KULICK, 2008; DUQUE, 2009).

Para além das normatizações e da função como um local possível de circulação e de existência, a pista proporciona a possibilidade de vivência dos riscos das violências e dos prazeres das experiências.

Como já discutido, os espaços familiares começam a se reconfigurar nas experiências de algumas dessas jovens, na medida em que o que antes era visto como impossibilidade e restrição, agora faz parte do cotidiano de algumas delas.

Estar em casa, com o salto nos pés ou escondido na bolsa, pode significar aceitação ou negação, reconhecimento ou deslegitimação, valorização ou vergonha, o que pode variar a depender do nível de investimento nos processos de travestilidade dentro e fora de casa, dos níveis de participação dos integrantes da família nestes processos, dos preceitos morais e religiosos de cada configuração doméstica, e das possíveis relaçôes que se estabelecem dentro de cada núcleo familiar.

De qualquer forma, o fato de a família poder se constituir como mais um dos imagináveis contextos de circulação e pertencimento tem rebatimentos nas vivências e experiências dessas jovens travestis, em relação a seus desejos, suas expectativas, suas histórias e suas futuras perspectivas.

Assim, o investimento no contato e na contribuição técnica que transponham os muros institucionais passa pela consideração da necessidade de valorização dos espaços de circulação dos sujeitos como potencial de reconhecimento de diferentes concepçóes e fazeres cotidianos, e da possibilidade de articulação e ressignificação dos próprios espaços.

Para Simone, Melissa, Claudinho e Jonas, a possiblidade de circulação nos espaços institucionais e nos diferentes territórios - ou a restrição desses diversos cursos - mostra a capacidade e o reconhecimento de normas, em determinados momentos mais ou menos explícitas, que se referem aos comportamentos, às subjetividades e às identidades esperadas e valorizadas em cada contexto.

Essas jovens, em diferentes níveis de conscientização, identificam os espaços pelos quais podem circular mais livremente e os espaços com relação aos quais 
devem ser mais cautelosas, conformando suas características corporais, subjetivas e identitárias, a depender das vontades e dos desejos em participar ou não de determinados espaços.

Quando essas jovens montam e remontam seus corpos, subjetividades e identidades, para além da explicitação de suas vontades e desejos, ficam evidentes os limites e possibilidades da articulação de cada corpo com seus espaços de circulação e de pertencimento. Os diferentes níveis de montagem problematizam os diversos níveis de aceitaçáo e/ou de negação das instituiçôes e dos próprios territórios, no que concerne a seus corpos, suas subjetividades e suas identidades.

Serem aceitas - ou não - nos diferentes espaços não repercute "apenas" na inserção ou na restrição da participaçáo e do exercício de direitos e da própria cidadania, mas, sobretudo, reverbera em suas próprias subjetividades, pois acabam por explicitar possibilidades e impossibilidades de "ir e vir" nos espaços privados e/ou públicos e, especialmente, a possibilidade ou impossibilidade de existir nesses locais.

\section{Referências}

ALMEIDA, M. C. et al. Terapia ocupacional e pessoas em situação de rua: criando oportunidades e tensionando fronteiras. Cadernos de Terapia Ocupacional da UFSCar, São Carlos, v. 19, n. 3, p. 351-360, 2011. http://dx.doi. org/10.4322/cto.2011.008.

BARBOSA, B. C. Nomes e diferenças: uma etnografia dos usos das categorias travesti e transexual. 2010. 130 f. Dissertação (Mestrado em Antropologia Social) - Universidade de São Paulo, São Paulo, 2010.

BARROS, D. D. Terapia ocupacional social: o caminho se faz ao caminhar. Revista de Terapia Ocupacional da Universidade de São Paulo, São Paulo, v. 15, n. 3, p. 90-97, 2004.

BARROS, D. D.; GHIRARDI, M. I. G.; LOPES, R. E. Terapia ocupacional social. Revista de Terapia Ocupacional da Universidade de São Paulo, São Paulo, v. 13, n. 3, p. 95-103, 2002.

BARROS, D. D.; ALMEIDA, M. C.; VECCHIA, T. C. Terapia ocupacional social: diversidade, cultura e saber técnico. Revista de Terapia Ocupacional da Universidade de São Paulo, São Paulo, v. 18, n. 3, p. 128-134, 2007.

BENEDETTI, M. R. Toda feita: o corpo e o gênero das travestis. Rio de Janeiro: Garamond, 2005.

BENTO, B. A reinvenção do corpo: sexualidade e gênero na experiência transexual. Rio de Janeiro: Garamond, 2006.

CRUZ, E. F. Banheiros, travestis, relaçôes de gênero e diferenças no cotidiano da escola. Revista Psicologia Política, São Paulo, v. 11, n. 21, p. 73-90, 2011.
DUQUE, T. Montagens e desmontagens: vergonha, estigma e desejo na construção das travestilidades na adolescência. 2009. 163 f. Dissertação (Mestrado em Sociologia) - Universidade Federal de São Carlos, São Carlos, 2009.

ELIAS, N. A sociedade de corte: investigação sobre a sociologia da realeza e da aristocracia de corte. Rio de Janeiro: Jorge Zahar Ed, 2001.

GEERTZ, C. Uma descrição densa: por uma teoria interpretativa da cultura. In: GEERTZ, C. A interpretação das culturas. Rio de Janeiro: Zahar, 1978. p. 13-41.

HAESBAERT, R. O mito da desterritorialização: do "fim dos territórios" à multi-territorialidade. Rio de Janeiro: Bertrand Brasil, 2004

HALL, S. A identidade cultural na Pós-Modernidade. Porto Alegre: DP\&A, 2006.

KULICK, D. Travesti - prostituiçäo, sexo, gênero e cultura no Brasil. Rio de Janeiro: Editora Fiocruz, 2008.

LOPES, R. E. et al. Juventude pobre, violência e cidadania. Saúde e sociedade, São Paulo, v. 17, n. 3, p. 63-76, 2008. http://dx.doi.org/10.1590/S010412902008000300008.

LOURO, G. L. Um corpo estranho. Ensaios sobre sexualidade e teoria queer. Belo Horizonte: Autêntica, 2004.

PAIS, J. M. Ganchos, tachos e biscates: jovens, trabalho e futuro. Porto: Âmbar, 2001.

PELÚCIO, L. Nos nervos, na carne, na pele: uma etnografia travesti sobre o modelo preventivo de aids. 2007. 264 f. Tese (Doutorado em Ciências Sociais) - Universidade Federal de São Carlos, São Carlos, 2007.

PERES, W. S. Subjetividade das travestis brasileiras: da vulnerabilidade da estigmatização à construção da cidadania. 2005. 201 f. Tese (Doutorado em Saúde Coletiva) - Universidade Estadual do Rio de Janeiro, Rio de Janeiro, 2005.

PERLONGHER, N. O negócio do michê. São Paulo: Fundação Perseu Abramo, 1987.

PRECIADO, B. Basura y género, mear/cagar. masculinolfemenino. Disponível em: <www.hartza.com/basura. htm>. Acesso em: 20 jan. 2014.

SILVA, H. R. S. Travesti: a invenção do feminino. Rio de Janeiro: Relume-Dumará, 1993.

TEIXEIRA, A. B. M.; RAPOSO, A. E. S. S. Banheiros escolares promotores de diferenças de gênero. In: SEMINÁRIO INTERNACIONAL FAZENDO GÊNERO: CORPO, VIOLÊNCIA E PODER, 8., 2008, Florianópolis. Anais... Florianópolis: UFSC, 2008. Disponível em: <http://30reuniao.anped.org.br/trabalhos/GT233472--Int.pdf >. Acesso em: 20 jun. 2013.

VILA, V. S. C. et al. Pesquisa etnográfica em saúde: sua apreciação por Comitês de Ética em Pesquisa. Revista da SOCERJ, Rio de Janeiro, v. 20, n. 3, p. 240-242, 2007. 


\section{Contribuição dos Autores}

Gustavo Artur Monzeli propôs a pesquisa, reuniu e analisou os dados, sob orientação, em todas as etapas, de Roseli Esquerdo Lopes e supervisão de Vitor Sérgio Ferreira, durante o período de estágio no Observatório Permanente da Juventude, no Instituto de Ciências Sociais da Universidade de Lisboa; ainda, elaborou inicialmente este texto, que teve a revisão crítica dos outros dois autores. Todos os autores aprovaram a versão final do texto.

\section{Notas}

${ }^{1}$ Este artigo é um dos desdobramentos da pesquisa de mestrado intitulada "Em casa, na pista ou na escola é tanto babado: espaços de sociabilidade de jovens travestis”, desenvolvida com o apoio da Fapesp (Fundação de Amparo à Pesquisa do Estado de São Paulo) - Processo № 2011/03536-3, cuja temática integrou o plano de trabalho de Estágio em Pesquisa no Exterior, igualmente financiado pela Fapesp (Processo № 2012/03162-9), vinculado ao Instituto de Ciências Sociais da Universidade de Lisboa.

${ }^{2}$ Com o intuito de fomentar a ação intersetorial para a juventude na cidade de São Carlos, a Prefeitura Municipal inaugurou, em 2008, o Centro da Juventude "Elaine Vivianne", equipamento social que prevê a articulação entre as Secretarias de Saúde, Educação, Cultura, Esportes e Lazer; sua coordenação está referenciada na Secretaria Municipal Especial da Infância e da Juventude e pretende-se que as açóes desse serviço criem e ampliem as alternativas de cultura, lazer, educação e profissionalização para os jovens da região da Grande Cidade Aracy.

${ }^{3}$ Termo criado por Peres (2005), referindo-se à variedade de processos identitários pelos quais sujeitos travestis passam para se constituírem como "femininos" e, mais além, não apenas para marcar sua heterogeneidade, mas também em substituição ao sufixo "ismo”, que remeteria a patologias. Este termo será utilizado sob rasura (HALL, 2006), na medida em que se insere em uma problemática queer, na qual um termo empregado sistematicamente para ofender, estigmatizar e desqualificar é utilizado como uma forma de ressignificá-lo (PELÚCIO, 2007).

${ }^{4}$ Nesta pesquisa, considerou-se, assim como Barbosa (2010), o termo "travesti” para pessoas que foram assignadas como nascidas do sexo masculino e que constroem o que consideram feminino em seus corpos.

${ }^{5}$ A escolha pelo uso do artigo no feminino se dá, assim como para Pelúcio (2007), tanto por uma posição política (relacionada às reivindicaçóes dos movimentos sociais) quanto por respeito à forma como elas próprias se tratam; mesmo quando se referindo ao nome masculino elas acabam por utilizar o artigo no feminino.

${ }^{6}$ Nomes fictícios.

${ }^{7}$ Esta avenida é conhecida por ser o principal ponto de prostituiçấo feminina, de mulheres e travestis, na cidade de São Carlos.

${ }^{8}$ Neste contexto, a expressão significa se passar por um rapaz.

${ }^{9}$ Peruca.

${ }^{10}$ Pênis.

${ }^{11}$ Cocaína.

${ }^{12}$ Se referindo à Gisele Bündchen, uma das principais modelos brasileiras, conhecida mundialmente.

${ }^{13}$ Cliente de programa que tem trejeitos masculinos, mas que, muitas vezes, é passivo no sexo (PELÚCIO, 2007). Pode se referir também aos clientes mais velhos.

${ }^{14}$ Geralmente se refere aos homens com trejeitos masculinos e que são mais fortes, praticantes de atividades de musculação.

${ }^{15}$ Melissa explica que o carro pode ser travado puxando o freio-de-máo ao mesmo tempo em que se tira a chave-de-contato do carro, desligando-o completamente.

16 "Pintosa" ou "dando pinta" se refere à pessoa homo-orientada que deixa transparecer, em seu comportamento, sua orientação sexual (PELÚCIO, 2007).

17 “Atender" pode se referir a realizar um programa ou mesmo fazer sexo não pago.

18 "Boys" pode se referir a garotos ou homens jovens.

${ }^{19} \mathrm{O}$ momento da "chamada" é quando os professores, no início ou no fim da aula, verificam a presença dos alunos a partir de uma lista com todos os nomes.

${ }^{20}$ Saudável no sentido de coerência entre sexo, gênero, corpo e sexualidade. 